\title{
Areal location of hazardous atmospheres simulation on toxic chemical release: A scenario-based case study from Ray, Iran
}

\author{
Farin Fatemi ${ }^{1,2}$, Ali Ardalan ${ }^{3,4}$, Benigno Aguirre ${ }^{5}$, Nabiollah Mansouri ${ }^{6}$, Iraj Mohammadfam ${ }^{7}$
}

${ }^{1}$ Department of Health in Disasters and Emergencies, School of Public Health, Semnan University of Medical Sciences, Semnan, Iran

${ }^{2} \mathrm{PhD}$ Candidate in Disaster and Emergency Health, Department of Disaster Public Health, School of Public Health, Tehran University of Medical Sciences, Tehran, Iran

${ }^{3} \mathrm{PhD}$, Associate Professor, Department of Disaster Public Health, School of Public Health, Tehran University of Medical Sciences, Tehran, Iran

${ }^{4}$ Harvard Humanitarian Initiative, Harvard University, Cambridge, United States of America

${ }^{5} \mathrm{PhD}$, Professor, Disaster Research Center, University of Delaware, Newark, DE, United States of America

${ }^{6} \mathrm{PhD}$, Professor, Department of HSE, Science, and Research Branch of Islamic Azad University, Tehran, Iran

${ }^{7} \mathrm{PhD}$, Professor, Department of Occupational Health, School of Public Health, Hamadan University of Medical Sciences, Hamadan, Iran

\section{Type of article: Original}

\begin{abstract}
Background and aim: Chemical accidents cause significant danger for residents living close to chemical facilities. For this reason, this study assessed the impacts of a simulated chemical accident on surrounding residents in the city of Ray, Iran.

Methods: In this scenario-based case study in 2015, the Areal Location of Hazardous Atmospheres (ALOHA) model was applied to simulate a toxic chemical release from a chlorine warehouse in Shourabad, Ray, Iran. The population of the area was calculated based on the latest census in Iran, 2011. The atmospheric variables included were wind speed, air temperature, and relative humidity. We also included data on pollution source such as diameter, length and volume, and condition of chemicals. The simulation was repeated for each seasonal period. The simulated threat zones were mapped using Geographical Information System. The percentage of residents sustaining injuries and death was calculated using probit.

Results: The maximum and minimum simulated threat zones by chlorine release are during summer and winter at 8.8 and 6.4 kilometers respectively. The total affected population was estimated at approximately 30,000 people. The greater percent of injuries and death was estimated to occur in the winter and autumn, compared to summer and spring, because of greater climatic instability. The number of individuals affected by chlorine release in the spring, summer, autumn and winter at 8.3, 8.8, 7.6 and 6.4 kilometers, are estimated at 22,500, 25,000, 28,100 and 27,500, respectively. Populations located in hot and warm zones of toxic chemical releases should have access to medical resources.

Conclusions: The results showed that relevant factors impact human vulnerability, and these should be examined to mitigate the harmful consequences of chemical accidents. Establishing a multi-level Emergency Response Program is also recommended in the area under study.

Keywords: Chemical hazard, Residential environment, Emergency response
\end{abstract}

\section{Introduction}

Iran, the $18^{\text {th }}$ largest country in the world, is located in the Middle East and has a workforce population of around 25 million (1). The pace of industrialization has speeded up over past decades in Iran, and is expected to increase (2).

\section{Corresponding author:}

Associate Professor Dr. Ali Ardalan, Department of Disaster Public Health, Head of Disaster Public Health Department, School of Public Health, Tehran University Medical of Sciences, Tehran, Iran.

Tel: +98.2188991108, Fax: +98.2188991108, Email: aardalan@razi.tums.ac.ir, and aardalan@gmail.com

Received: September 08, 2016, Accepted: February 28, 2017, Published: October 2017

iThenticate screening: January 30, 2017, English editing: March 27, 2017, Quality control: September 14, 2017

(C) 2017 The Authors. This is an open access article under the terms of the Creative Commons Attribution-NonCommercialNoDerivs License, which permits use and distribution in any medium, provided the original work is properly cited, the use is non-commercial and no modifications or adaptations are made. 
This process meant that chemicals are produced, transported and stockpiled near residential areas, increasing concerns over public safety associated with explosions, leakages, and release of chemicals (3-4). Chemical accidents can occur in varying conditions with different intensities. In Iran in 2014, over 230 people were hospitalized after inhaling toxic gas in the city of Zahedan, south of Iran (5). In 2001, the accidental chlorine release in the water treatment station of Tehran killed 2 and injured 50 people (6). Leakage of chlorine during transportation in the north of Iran in 1995 killed 3, and 200 residents had to receive medical assistance (7). These types of chemical accidents are of concern in other countries. Chemical accidents in Seveso (Italy), Flixborough (United Kingdom) and Bhopal (India) killed and injured thousands of people, and caused serious health hazards and irreversible environmental damage (8-10). Tehran is an industrial province with more than 17 industrial parks, and it is highly likely to witness chemical accidents (11). One of its industrial zones is Shourabad, which is located in the city of Ray in Tehran province, and has a population of about 4000 people. It contains more than 200 chemical manufacturing plants and warehouses that stock various types of chemicals such as chlorine, ammonia, petroleum, and acids. Moreover, these plants are situated in the vicinity of residential areas. In all of these and other cases, a proactive approach to disaster mitigation and risk management is needed to prevent and mitigate potential harmful consequences (12-14). Various types of risk assessment studies such as scenarios simulation methods or measuring risk tolerance play a major role in emergency management, and may be carried out in connection with such a proactive approach. Information produced in risk assessment studies can be applied in decision making in real-time during an emergency (15). The extent to which chemical plants could forecast the scale of their threat zones in cases of explosions or chemical releases, enables them to better estimate and minimize the risks involved. These relevant studies have facilitated disaster mitigation and response preparations in these threatened areas up to now, and have perhaps lessened the degree of impact of toxic gas on residents (16). Thus, the rationale for this study is to simulate, in an Iranian context, the scale of threat zones in the event of chlorine release, and estimate the percentage of injuries or deaths in the study area. We hope to estimate the magnitude and severity of the chemical hazard in this study in the hope of convincing the decision makers to allocate the necessary resources in the understudy area.

\section{Material and Methods}

This study conducted a scenario based in Shourabad, Ray city, Tehran province in 2015. First, the area under study was examined due to its high density of chemical manufacturing plants and warehouses and also because of the kind of chemicals that were involved. The population of the area was calculated from the 2011 Iran census. More specifically, the chlorine warehouse in Shourabad was chosen as the subject of simulation in view of the accidents involving the release of chlorine elsewhere in Iran, as well as the widespread use of chlorine in different industrial procedures.

\subsection{Areal Locations of Hazardous Atmosphere (ALOHA) simulation}

Second, a probable scenario during nighttime hours was simulated in the study area so as to obtain the threat zone's toxic vapor dispersion, using the ALOHA 5.4.4 model. (This model is capable of simulating the dispersion of chemical vapor for over 900 chemicals). Moreover, rather than daytime, the model is used during the nighttime which has more atmospheric instability, and more regions are affected by chemical releases.

\subsection{Characteristics of $\mathrm{ALOHA}$ simulation}

The ALOHA model was chosen for simulation because the required data is not extensive even though the accuracy of predictions is appropriate (17). The ALOHA model is suitable for rapid deployment by emergency responders that may be pressed for time (18). The official Iran meteorological organization provided the values of required meteorological parameters for ALOHA modeling for the different seasons of a year. The registered data were available from January 1951 to December 2012 in monthly mean values. The input data were entered manually into the ALOHA software in two sections. The model selected the best fit for stability class from the information inputted.

\subsubsection{Atmospheric data}

Atmospheric data included wind speed and direction, wind measurement height, ground roughness, cloud cover, air temperature and relative humidity. The yearly mean values were calculated and used for wind speed, air temperature, and relative humidity.

\subsubsection{Source data}

A chlorine tank, as a contamination source, was selected based on the scenario in this study. Tank characteristics were its diameter, length and volume, the state of the chemical, ambient temperature, and the shape and diameter of the opening through which the pollutant could exit. 


\subsection{Determining Acute Guideline Exposure Levels (AEGLs)}

After determining the physical scale of threat zones, the outputs of ALOHA are mapped using a Geographical Information System (GIS) with access to the best possible information from the hazard areas (AEGLs). The simulated threat zones are each divided into 3 zones, so as to help first responders to chemical accidents. ALOHA uses AEGLs as the default level for chlorine.

\subsubsection{Acute Guideline Exposure Level 3}

AEGL-3 (Red zone) is the airborne concentration of a substance, above which, it could have life-threatening health effects or death.

\subsubsection{Acute Guideline Exposure Level 2}

AEGL-2 (Orange zone) is the airborne concentration of a substance for which the prediction is that the general population, including susceptible individuals, could experience irreversible or other serious, long-lasting adverse health effects or an impaired ability to escape.

\subsubsection{Acute Guideline Exposure Level 1}

AEGL-1 (Yellow zone) is the airborne concentration of a substance, above which, the general population, including susceptible individuals, could experience notable discomfort, irritation, or certain asymptomatic nonsensory effects which are transient and reversible upon cessation of exposure.

\subsection{Estimating fatalities in the understudied area}

The percentage of injuries or death in the threat zones was estimated using probit equations (19). The concentration of chlorine gas, corresponding to a percentage of fatalities in the exposed population is calculated via probit.

\subsection{Ethical Consideration}

The information of investigated documents, companies and warehouses were kept secret by the authors.

\section{Results}

The ALOHA model is employed to simulate a chlorine release in Shourabad. A 1-ton cylinder of chlorine is assumed damaged during incorrect handling, causing the release of its content into the air at nighttime. Nighttime is the period from 1 hour before sunset to 1 hour after sunrise. The simulation computed the range of toxic vapor, assuming the release in one hour of the contents from the damaged cylinder. Table 1-2 and Figures 1-4 show the environmental configurations and outputs of ALOHA simulation. Figures 1-4 demonstrate the implementation of ALOHA simulated threat zones in a GIS presentation. The result showed that seven villages and two cities were affected by the chemical release, based on the scenario selected. The number of individuals affected by chlorine release in the spring, summer, autumn and winter at 8.3, 8.8, 7.6 and 6.4 kilometers, are estimated at 22,500, 25,000, 28,100 and 27,500, respectively. The maximum and minimum concentrations of chlorine gas in the red zone (Immediately Dangerous to Life or Health (IDLH) or AGEL-3), orange zone (AGEL-2) and yellow zone (AGEL-1) and the percentage of injuries and death, are calculated using the ALOHA diagrams and equations $(1,2)$.

Table 1. Configurations of the release scenario for the seasonal simulation

\begin{tabular}{|c|c|c|c|c|}
\hline \multirow[t]{2}{*}{ Parameters } & \multicolumn{4}{|l|}{ Season } \\
\hline & Spring & Summer & Autumn & Winter \\
\hline Air temperature $\left({ }^{\circ} \mathrm{C}\right)$ & 16.5 & 29.5 & 18.5 & 4.8 \\
\hline Relative humidity (\%) & 40 & 26 & 37 & 61 \\
\hline Wind speed (knots) & 6.8 & 5.6 & 4.4 & 4.1 \\
\hline Wind direction & $\mathrm{SW}^{*}$ & SW & SW & SW \\
\hline Elevation of wind speed measurement (m) & 10 & 10 & 10 & 10 \\
\hline Ground roughness & Open country & Open country & Open country & Open country \\
\hline Atmospheric stability class & $\mathrm{D}$ & $\mathrm{D}$ & $\mathrm{F}$ & $\mathrm{E}$ \\
\hline Cloud cover $(0-10)$ & 5 & 0 & 5 & 7 \\
\hline Total volume released $(\mathrm{kg})$ & 1000 & 1000 & 1000 & 1000 \\
\hline Model of release & Heavy gas & Heavy gas & Heavy gas & Heavy gas \\
\hline Total duration (min) & 60 & 60 & 60 & 60 \\
\hline
\end{tabular}

*South West 
Table 2. Threat zones, concentration, percent of injuries and deaths of toxic substance release in Shourabad, Ray city, Iran

\begin{tabular}{|l|l|l|l|l|}
\hline Season & Threat zones & Distance $(\mathrm{km})$ & Concentration (Min-Max $(\mathrm{ppm})$ & Injury, Death (Min-Max (\%) \\
\hline \multirow{3}{*}{ Spring } & AGEL-3 (IDLH) & 1.9 & $21-30000$ & $4-38$ \\
\cline { 2 - 6 } & AGEL-2 & 4.8 & $3.5-20$ & $0-3.7$ \\
\cline { 2 - 6 } & AGEL-1 & 8.3 & $<0.5$ & 0 \\
\hline \multirow{3}{*}{ Summer } & AGEL-3 (IDLH) & 2 & $22-150000$ & $4.2-45.2$ \\
\cline { 2 - 5 } & AGEL-2 & 5 & $2.1-21$ & $0-4$ \\
\cline { 2 - 5 } & AGEL-1 & 8.8 & $<0.5$ & 0 \\
\hline \multirow{5}{*}{ Autumn } & AGEL-3 (IDLH) & 1.7 & $35-150000$ & $6.3-45.2$ \\
\cline { 2 - 5 } & AGEL-2 & 4.4 & $2.1-34$ & $0-6.2$ \\
\cline { 2 - 5 } & AGEL-1 & 7.6 & $<0.4$ & $3.7-53$ \\
\hline \multirow{3}{*}{ Winter } & AGEL-3 (IDLH) & 1.5 & $20-800000$ & $0-3.5$ \\
\cline { 2 - 5 } & AGEL-2 & 3.7 & $2.1-19$ & 0 \\
\cline { 2 - 5 } & AGEL-1 & 6.4 & $<0.5$ & \\
\hline
\end{tabular}

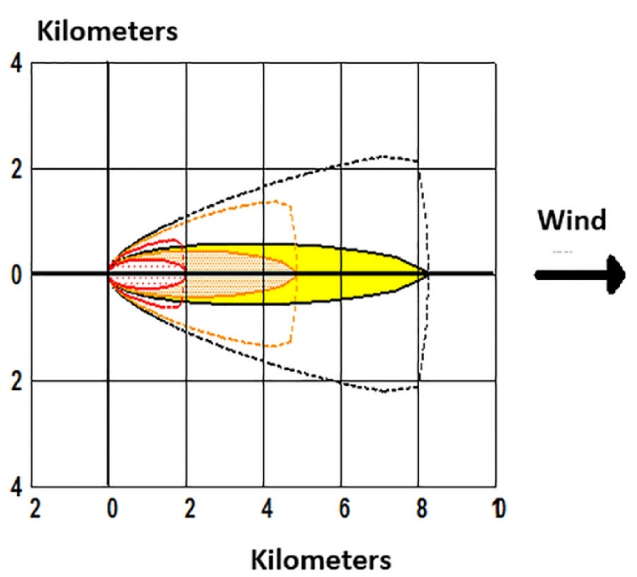

Greater than $20 \mathrm{ppm}$ (AEGL-3 [60 min]) Greater than 2 ppm (AEGL-2 [60 min]) Greater than $0.5 \mathrm{ppm}$ (AEGL-1 [60 $\mathrm{min}])$

Wind direction confidence line

Figure 1. Chlorine release scenario; Spring

\section{Kilometers}

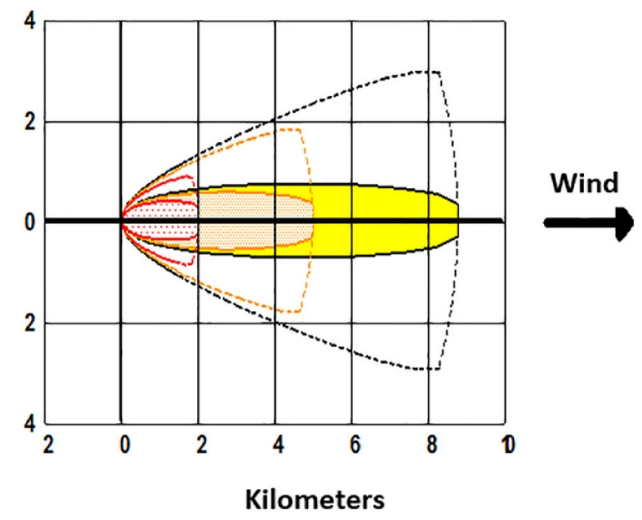

Greater than 20 ppm (AEGL-3 [60 min]) Greater than 2 ppm (AEGL-2 [60 min]) Greater than $0.5 \mathrm{ppm}$ (AEGL-1 [60 min])

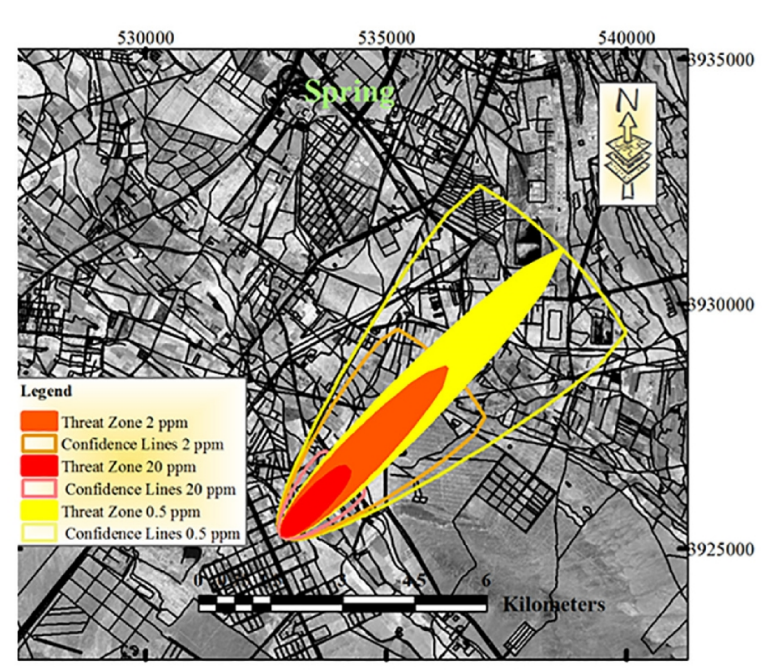

Wind direction confidence line

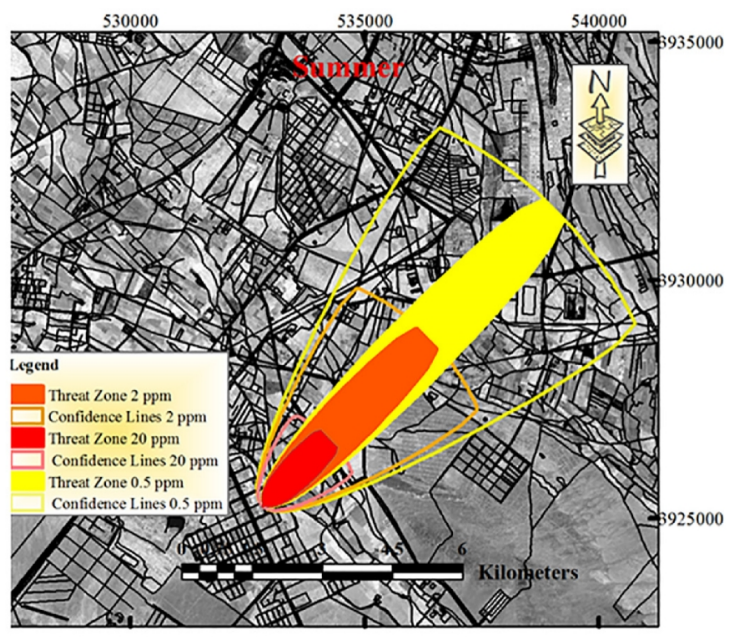

Figure 2. Chlorine release scenario; Summer 

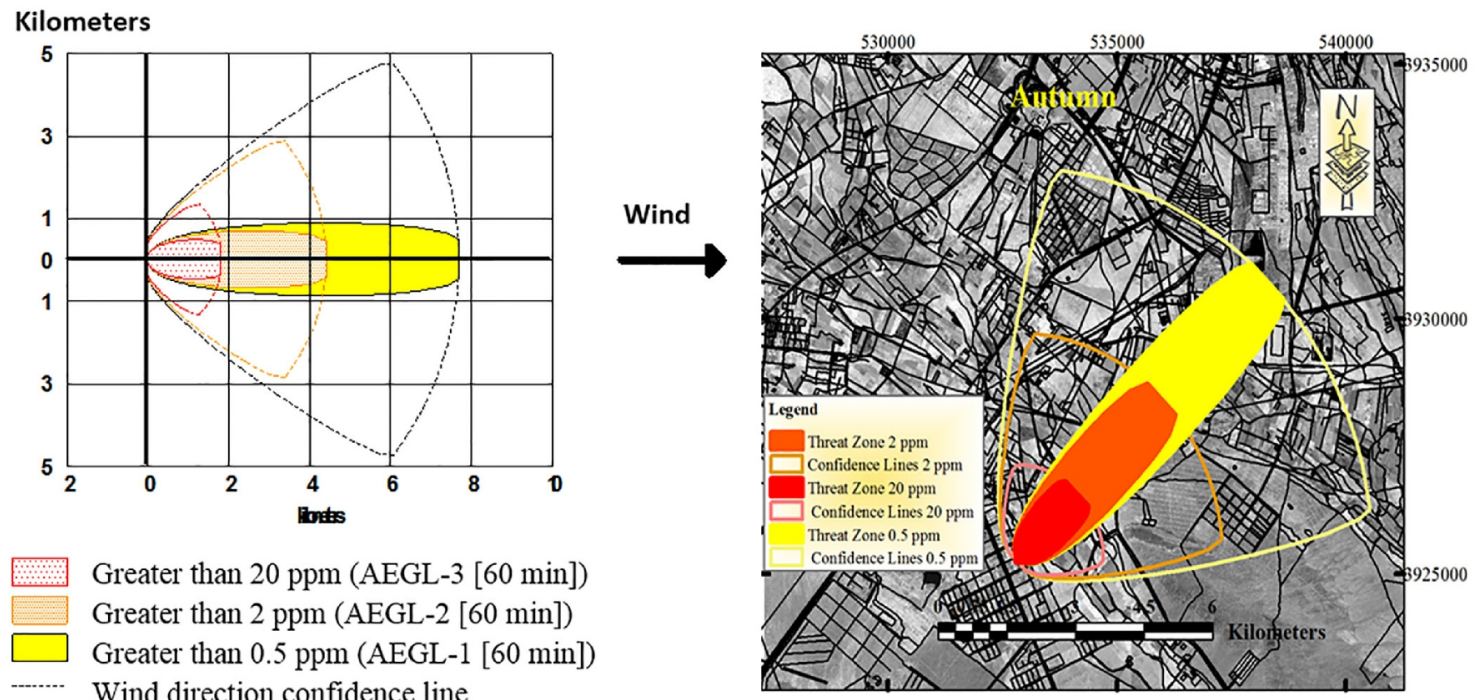

Figure 3. Chlorine release scenario; Autumn
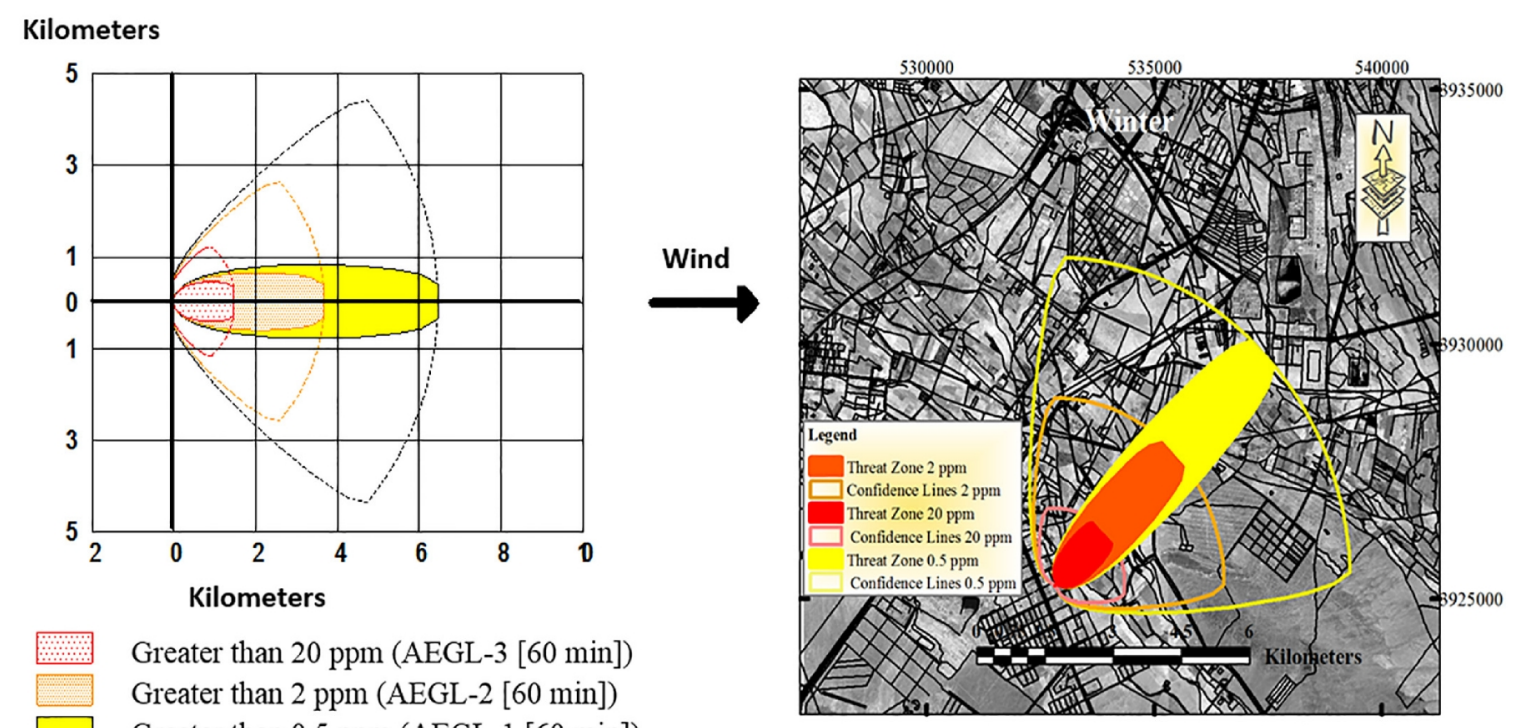

Greater than $20 \mathrm{ppm}$ (AEGL-3 [60 min]) Greater than 2 ppm (AEGL-2 $[60 \mathrm{~min}])$ Greater than $0.5 \mathrm{ppm}$ (AEGL-1 [60 $\mathrm{min}]$ )

Wind direction confidence line

Figure 4. Chlorine release scenario; Winter

\section{Discussion}

The results showed that in the case of the release of chlorine gas, large areas, and many people were in danger. Based on the results of dispersion simulation for a scenario of a toxic chemical accident, the leak of chlorine during the summer, had the greatest threat zone, followed by the release of chlorine during the spring. The maximum and minimum number of people exposed to health risks by chlorine release, estimated in the autumn and spring, is 25,400 , and 24,100 people at 6.5, and 8.8 kilometers, respectively. Despite slower wind speed in the autumn, because of greater climatic instability in comparison to spring, a larger number of regions tended to be affected by the chemical in their surroundings, leading to an increased number of affected people. The highest percentage of injuries and death, 6.3 to 45.2 , were also calculated for autumn. This estimation depends on the concentration of chlorine in the air and also in the distance to the source of the contamination. Population locating in AGEL-3 (IDLH) and AGELl-2 zones, encounter death or severe health problems most frequently, and must receive medical assistance as soon as possible. In all seasons, sustainable injuries and death for AGEL-1 zone have been estimated at $0 \%$ in this study. Horng et al. found that residents without enough time to escape should shelter in places in the areas with a maximum concentration of chlorine up to 3 ppm at AEGL-1 (20). Another study recommended that the areas 
in which chlorine concentration is greater than 3 ppm at AEGL-2 and AEGL3 should be equipped with evacuation plans (21). In the area of study at present, there are no safe places that can act as shelters. Nor is there an evacuation plan in case of chemical accidents. Risk communication and evacuation routes to populations living in these areas are essential. They should have information about hazards in the vicinity and the protective actions that they can take if a chemical incident occurs (22-23). For instance, many lives would have been saved in the Bhopal accident, if people had been aware of the simple safety measure to stay in an enclosed space with wet cloths on their faces (24). The results of these studies should be combined with an Emergency Response Planning (ERP) for dealing with accidents for which there is limited response time (25). Strong reporting and analysis of chemical accidents will help to establish a national chemical database (26). This surveillance system should be able to identify high-risk locations, provide early detection of significant events, as well as planning ERP that is the distinction between chemical incidents and natural disasters such as earthquakes (27-29). Based on the threat zones and their numerous harmful impacts, ERP could be adjusted at several levels with each of them requiring a separate set of guidelines for activation at the time of crisis (30). As a basic element for understanding the risk of chemical disasters, knowing the level of exposure is not the only critical factor. Calculating the degree of vulnerability is also a key issue for research on emergency management (31). In addition to having an appropriate ERP, it is necessary to consider human vulnerability factors such as old age or illnesses, and match the available capacities with the criteria in further studies.

\section{Conclusions}

At the initial stage of risk assessment, simulating the pattern of toxic vapor dispersion using the ALOHA model, was essential in this study. The statistics from the simulation based on AGELs and using the probit equations, not only served as a useful reference for disaster management, but also were the basis for notifying residents in the affected areas to take necessary safety precautions to ensure the safety of their lives and properties. Preparing multi-level ERP, according to threat zones in the field under study, is vital. On the other hand, determining the presence and extent of human vulnerability factors could mitigate the potential chemical harms for residents living in proximity to industrial installations and complete the risk assessment process.

\section{Acknowledgments:}

This study is the part of Ph.D. dissertation and the authors wish to acknowledge the grammatical revision of the manuscript in English facilitated by the Consultation Unit, Office of Publications and Scientometrics, Tehran University of Medical Sciences.

\section{Conflict of Interest:}

There is no conflict of interest to be declared.

\section{Authors' contributions:}

All authors contributed to this project and article equally. All authors read and approved the final manuscript.

\section{References:}

1) Sadeghi F, Bahrami A, Fatemi F. The Effects of Prioritize Inspections on Occupational Health Hazards Control in Workplaces in Iran. J Res Health Sci. 2014; 14: 282-6. PMID: 25503284.

2) Mahdavi A, Azizmohammadlou H. The effects of industrialization on social capital: the case of Iran. International Journal of Social Economics. 2013; 40(9): 777-96.

3) OECD Guiding Principles for Chemical Accident Prevention, Preparedness, and Response, Paris: OECD Environment, Health, and Safety Publications; 2003.

4) Fullwood RR. Chapter 9-Chemical Process Accident Consequence Analysis. Woburn: ButterworthHeinemann; 2009.

5) Kayhan news. Zahedan's toxic gas release was the first such an incident. Iran: 2014.

6) Adl J, Mohammadfam I, Nezamodini Z. Risk assessment of Chlorine gas release in the drinking water treatment stations in Tehran with fault tree analysis. Scientific Medicine Journal. 2007; 6: 468-78.

7) Mihailidou E, Antoniadis K. Assael M. The 319 Major Industrial Accidents Since 1917. International Review of Chemical Engineering. 2012; 4: 529-40.

8) Souza Porto MF, Freitas CM. Major Chemical Accidents in Industrializing Countries: The Socio-Political Amplification of Risk. Risk Anal. 1996; 16(1): 19-29. doi: 10.1111/j.1539-6924.1996.tb01433.x. PMID: 8868221 . 
9) Meel A, O'neill LM, Levin JH, Seider WD, Oktem U, Keren N. Operational risk assessment of chemical industries by exploiting accident databases. J Loss Prev Process Ind. 2007; 20(2): 113-27. doi: 10.1016/j.jlp.2006.10.003.

10) Dhara VR, Dhara R. The Union Carbide disaster in Bhopal: a review of health effects. Arch Environ Health. 2002; 57(5): 391-404. doi: 10.1080/00039890209601427. PMID: 12641179.

11) Zonooz HB, Barmaki A. Identification of industrial clusters in Tehran province. Quarterly Journal of Quantitative Economics. 2011; 8(1): 1-22.

12) Ardalan A. Evidence-Based Integration of Disaster Risk Management to Primary Health Care, the Case of I.R. Iran. UNISDR. $2014 . \quad$ Avilable from: http://www.preventionweb.net/files/workspace/7935_ardalanirancasestudy.pdf.

13) Rikhtegar N, Mansouri N, Oroumieh A, Chamzini A, Zavadskas E, Kildien S. Environmental impact assessment based on group decision-making methods in mining projects. Economic Research. 2014; 27(1): 378-392. doi: 10.1080/1331677X.2014.966971.

14) Mohammadfam I, Saraji G, Kianfar A, Mahmoudi Sh. Developing the health, safety and environment excellence instrument. Iranian J Environ Health Sci Eng. 2013; 10(1): 7. doi: 10.1186/1735-2746-10-7. PMID: 23369610, PMCID: PMC3561110.

15) Heino P, Kakko R. Risk assessment modeling and visualization. Safety Science. 1998; 30: 71-7. doi: 10.1016/S0925-7535(98)00037-X.

16) Sanchez EY, Colman JE, Porto A, Jacovkis PM. Emergencies planning and response: Coupling an exposure model with different atmospheric dispersion models. Atmospheric Environment. 2013; 79: 48694. doi: 10.1016/j.atmosenv.2013.07.013.

17) Guarnaccia J, Hoppe T. Off-site toxic consequence assessment: A simplified modeling procedure and case study. J Hazard Mater. 2008; 159(1): 177-84. doi: 10.1016/j.jhazmat.2007.09.123. PMID: 18053643.

18) O’Mahony MT, Doolan D, O'Sullivan A, Hession M. Emergency planning and the Control of Major Accident Hazards (COMAH/Seveso II) Directive: An approach to determine the public safety zone for toxic cloud releases. J Hazard Mater. 2008; 154(1-3): 355-65. doi: 10.1016/j.jhazmat.2007.10.065. PMID: 18078713.

19) Macfarlane D, Ewing T. Acute health effects from accidental releases of high toxic hazard chemicals. Loss Prev Process Ind. 1990; 3: 167-76. doi: 10.1016/0950-4230(90)85041-7.

20) Horng JJ, Lin YS, Chi MT. Using consequence analysis on some chlorine operation hazards and their possible effects on neighborhoods in central Taiwan. J Loss Prev Process Ind. 2005; 18(4-6): 474-80. doi: 10.1016/j.jlp.2005.07.024.

21) Wattigney A, Rice N, Cooper L, Drew JM, Orr MF. State programs to reduce uncontrolled ammonia releases and associated injury using the hazardous substances emergency events surveillance system. J Occup Environ Med. 2009; 51(3): 356-63. doi: 10.1097/JOM.0b013e318197368e. PMID: 19225422.

22) Phillips BD, Morrow BH. Social science research needs: Focus on vulnerable populations, forecasting, and warnings. Nat Haz Rev. 2007; 8(3). doi: 10.1061/(ASCE)1527-6988(2007)8:3(61).

23) Wolkin A, Patterson JR, Harris S, Soler E, Burrer S, Mcgeehin M, Greene S. Reducing Public Health Risk During Disasters: Identifying Social Vulnerabilities. JHSEM. 2015; 12(4): 809-22. doi: 10.1515/jhsem2014-0104.

24) Manual for the Public Health Management of Chemical Incidents. Geneva, Switzerland: World Health Organization; 2009.

25) Tseng JM, Su TS, Kuo CY. Consequence evaluation of toxic chemical releases by ALOHA. Procedia Eng. 2012; 45: 384-9. doi: 10.1016/j.proeng.2012.08.175.

26) Olowokure B, Pooransingh S, Tempowski J, Palmer S, Meredith T. Global surveillance for chemical incidents of international public health concern. Bulletin of the World Health Organization. 2005. Available from: https:/questia.com/library/journal/1G1-140748304/global-surveillance-for-chemicalincidents-of-international.

27) Bowen HJ, Palmer SR, Fielder HM, Coleman G, Routledge PA, Fone DL. Community exposures to chemical incidents: development and evaluation of the first environmental public health surveillance system in Europe.

J Epidemiol Community Health. 2000; 54(11): 870-3. PMID: 11027203, PMCID: PMC1731586.

28) Abbaspour M, Shafiepour M, Mansouri N. The comprehensive program for controlling the environmental health hazards triggered by chemical accidents. Environment health science and technology. 2003; 21: 1-9. 
29) Aliabadi SF, Sarsangi A, Modiri E. The social and physical vulnerability assessment of old texture against earthquake (case study: Fahadan district in Yazd City). Arab J Geosci. 2015; 8(12): 10775-10787. doi: 10.1007/s12517-015-1939-8.

30) Mortazavi B, Parsarad M, Asilian H, Khavanin A. Evaluation of chlorine dispersion from a storage unit in a petrochemical complex to providing an emergency response program. Iran Occupational Health. 2011; 8: 68-77.

31) Yinghui H, Bo S, Jujie C. Study on Vulnerability Assessment of Public Health Emergency Management 4th International Conference on Information Systems for Crisis Response and Management; Harbin Eng Univ, Harbin: Peoples R China, 2010. 